Gadjah Mada International Journal of Business

January 2002, Vol. 4, No. 1, pp. 17-30

\title{
THE INFLUENCE OF CHANGE AGENTS ON INFORMATION TECHNOLOGY DIFFUSION IN FIRMS
}

\section{Hargo Utomo}

The role of change agents in technological diffusion and innovation at firm level has been addressed in published literature mostly within the context of the developed countries. However, the involvement of change agents in the diffusion and adoption of IT-based innovations by small and medium-sized firms in the developing countries is largely unexplored. The main research questions are why and how management decisions to adopt and use IT are influenced (if any) by the interactions of key people in firms with several identified change agents. Case studies are used as the preferred approach to answer the research questions and to understand the qualitative aspects of IT diffusion at the level of the firm. The study concludes that IT diffusion in small and medium-sized firms expose mixed institutional influences. The mechanism by which change agents are involved in IT diffusion is also unique and is claimed to be different from that is generally found in other studies in this area. Some policy implications are proposed by this study.

Keywords: diffusion; innovation; IT; SMFs

\footnotetext{
* The earlier version of the paper had been presented at the Second Global Information Technology Management (GITM) World Conference, Dallas, Texas, USA, 10-12 June 2001.
} 


\section{Introduction}

This paper examines the influence of change agents on the diffusion of information technology (IT)-based innovations within the context of small and mediumsized firms (SMFs) in Indonesia. The paper addresses questions of why and how management decisions to adopt and use IT are influenced (if any) by the interactions of key people in firms with several identified change agents, including business consultants, business associates/friends, leaders of government authorities and academics. The numbers and commercial significance of firms in Indonesia identify them as being particular interest for research into the mechanism by which these change agents influence IT diffusion.

The idea of involving the role of change agents in technological innovation is not entirely new, especially in the sense that if it derives from the experience of firms in developed countries (for example Hanna et al. 1995; Gregor and Jones 1997; Bode and Burn 2000). However, the involvement of change agents in the diffusion of IT by SMFs in the developing countries is largely unexplored. This is, in fact, much more complicated and brings more consequences than those identified in the developed countries.

Indonesia is used as a case study to represent the complexity of IT diffusion by firms in developing countries. Moreover, SMFs in Indonesia have played a pivotal role in supporting economic growth and employment creation. These firms constitute at least 85 percent of all industrial establishments in the country and contributed to around 21 percent of total value added and 53 percent of total employment over the period 1985-1997 [Indonesia Central Bureau of Statistics (BPS) 1997]. Hence, a study which analyses the mechanisms by which change agents influence the process of IT diffusion is not only important but is also timely for the country in keeping up with the demand for technological sophistication. Moreover, the process is seen to be different from that observed in other parts of the world.

The paper is organized as follows. The next section introduces and outlines the concept of change agents and its relevance to the diffusion of technological innovation in Indonesia. The research approach taken and methods used in data collection are described. Research findings along with some anecdotal evidence gathered from the fieldwork are then analyzed. The last section draws conclusions and implications of the findings.

\section{Research Context and Background}

The term "change agents" used in this paper refers to individuals and social entities that have formally been given primary responsibility for helping management to plan and orchestrate change in firms (Rogers 1995). Change agents may have one or more of the following characteristics: They are confident, supportive, role models, and expert in subject matter (Holman and Devane 1999). These characteristics are attached to professional occupation such as consultants and educators or are linked to institutions such as industry associations and government-supported institutions (see Dodgson and Bessant 1996).

As described by Rogers (1995), the diffusion of technological innovation in firms is a kind of social change by which cooperation among members of the firms, who commonly have divergent views toward technological innovation, accept possible alteration within internal systems, 
processes or procedures. Change agents may have the capacity to orchestrate divergent views amongst people in firms, as well as to cope with social uncertainty and other externalities, such as social costs associated with coordination between firms and relevant institutions as a result of adopting IT-based innovations (Thong et al. 1996).

Thong and Yap (1996) explain that the involvement of external experts is very important in the implementation of information systems and technology in small businesses. These firms usually do not have internal IS/IT department. Hence, the involvement of external experts is relevant to reduce the level of resistance amongst the key people in firms toward IT-based innovations. Bode and Burn (2000) advances the issue by describing how consultants can be involved in the implementation of web-based technology in small firms. They argue that the role of consultants is crucial not only in assessing the need for adopting web-based technology, but also in monitoring all aspects of IT implementation in firms.

The role of educators in promoting technological innovation also cannot be overlooked (Sam et al. 1999). Many studies show that attitudes, beliefs, and behavior of educators toward IT innovation affect their intention to promote computer literacy amongst students (for example: Peter 1999; Ridzuan and Alias 1999). Moreover, alliances between industry and educational institutions can prepare and equip graduates to fulfill the demand for skilled labor from industry (Etzkowitz et al. 2000; Etzkowitz and Leydesdorff 2000). This phenomenon leads to the evolving of customer-oriented educational institutions by which educators may design their curricula and teaching systems to meet the demand from potential employers.
The influence of customers or business patrons on IT diffusion has been discussed in a number of studies. These address for example in the adoption of web-technology (Lai-Yee and Pendse 1997); EDI (Parker and Swatman 1997) and electronic commerce (Chan and Swatman 1999). These studies are concerned with the importance of educating customers, both individual and institutional, in relation to improving their knowledge and subsequently on the level of acceptance of IT innovation. Moreover, Swan et al. (1999) examine the influence of technology suppliers and professional associations as central agencies in shaping the diffusion process of Computer-Aided Production Management (CAPM) in the United Kingdom and Sweden.

Another potential change agent in the implementation of IT innovations is government-supported institutions (King et al. 1994; Yap et al. 1994; Hanna et al. 1996; and Yap and Thong 1997). The government may perform one or more of the following major functions: supplier of technological information, chief regulator, provider of financial assistance, initiator of major R\&D projects, and protector of intellectual property rights. However, the level and range of involvement of government-supported institutions in IT diffusion and adoption by firms vary between one country and another (see Montealegre 1999). A centralized government tends to perform the whole range of functions, whilst in a more democratic country the involvement of government in IT diffusion tends to evolve in line with a market-driven structure (Jandos and Uhlir 2000; Kangas 2000).

In the context of Indonesia, several initiatives have been developed by both public and private institutions to promote IT diffusion. The government's interven- 
tion in IT encourages the technological learning process and stimulates its strategic development in many aspects of the country. For example, several governmentsupported institutions and ministries are involved in setting up general initiatives whilst private institutions are interested in practical implementation especially in promoting IT at local government. The Ministry of Industry and Trade (MIT) through the Directorate General of Small-Scale Industry, in cooperation with PT. Pos Indonesia, has developed an information systems kiosk program to encourage public awareness of Internet technology. Meanwhile, under the coordination of the Ministry of Research and Technology, several government initiatives are also being pursued to promote the diffusion of networking technology through empowerment of the Indonesian Institute of Science, the National Aerospace Agency, and the Agency for Assessment and Application of Technology.

Moreover, the diffusion of IT in Indonesia is being facilitated by an increasing number of Internet service providers. According to the Indonesian Internet Service Provider Association, ${ }^{1}$ there are currently 35 Internet service providers operating in Indonesia, whilst another 15 providers will be in the business shortly, totalling 50 Internet service providers by the end of 2001. However, the current level of Internet penetration in Indonesia is still far behind the level of penetration in other Asian countries despite the growth in numbers of Internet users. For example, the number of Internet hosts or computers with active Internet Protocol(IP) addresses connected to the Internet in Indonesia is only 0.76 per 10,000 people, compared to the Philippines, which has 1.29, Thailand 4.49, Malaysia 23.5, and Singapore 322.2. Meanwhile, the average number of Internet hosts in East Asian and Pacific countries is 2.39 compared to the average number of Internet hosts in the entire the world 94.4 per 10,000 people (The World Bank 2000).

Despite growing concerns about the role of external change agents, as discussed above, recent studies have attempted to open new frontiers by exploring internal factors of firms which foster ways of IT diffusion. For example, Utomo (2000) demonstrates that internal factors such as the level of IT knowledge amongst key people in firms which has significantly influenced the diffusion rate and improved the extent to which SMFs adopt and use IT. Perceived impacts of IT, combined with strong attitudes of key people in firms towards organizational learning and change management, also contribute to boosting IT diffusion in firms (Harrison et al. 1997; O'Callaghan 1998; Utomo and Dodgson 2000) although it is difficult to single out which factor(s) strongly affect the other.

Meanwhile, recent developments within institutional theory highlight the importance of social networks and political struggles amongst members of firms (Hughes et al. 1996). This development raises major implications for empowering internal firms' capability to gain optimum benefits of technological innovation. The importance of networks is articulated in numbers of situations where institutions need to develop its internal capability in order to access external knowledge and expertise. The social networks provide an interface through which members of the institutions may acquire and implement

\footnotetext{
${ }^{1}$ Further information about the Indonesian Internet Service Provider Association can be found at http:// www.apjii.or.id/ (Accessed 5 October 2000).
} 
external ideas on the diffusion of the innovation process. This suggests that the idea of 'learning by learning' as opposed to 'learning by doing' amongst employees or internal staff accelerates the diffusion of the innovation process at the level of the firm.

As conclusion, previous studies on the role and function of change agents in relation to IT diffusion were diverse. Many studies are mainly concerned with the roles of external forces on IT diffusion and have discounted firms' internal capabilities to respond proactively to institutional influences. Previous studies also focused on identifying the influence of formal institutions as change agents, with less attention being placed on assessing the influence of informal constituents on the diffusion of technological innovation. Although there is a continuing debate over the type of change agents that may significantly affect the diffusion of IT, the influence of specific agents such as social institutions in the form of business associates and friends is still not adequately addressed. Further investigation that considers this particular aspect as well as the integration of various change agents will enhance general understanding concerning the influence of institutional factors on IT diffusion. The next section provides empirical evidence for validating a framework through which the influence of institutional networks on technological diffusion in Indonesia is explored.

\section{Research Approach}

As suggested by Yin (1993, 1994), case studies are used as the preferred approach to answer the research questions which are employed not only to investigate the 'why' and 'how'-type questions, but also and to understand the qualitative aspects of IT diffusion at the level of the firm. A single firm then is used as the unit of analysis. The study used semistructured interviews, note taking, and tape recording as methods of collecting data. Research findings are based on triangulation of interviews with designated people within firms and on extraction of selected documentation of information gathered from newspapers, business magazines, professional journals as well as company reports. All interviews were conducted by the same researcher to minimize investigator bias.

Sample firms were drawn from two general categories of industry: "high-tech" (machinery, metal works, industrial parts and components) and "low-tech" (food processing and wood products) in various industrial clusters in Central and East Java provinces which are hosts of many SMFs in Indonesia. By focusing on two general categories, it is hoped that the study will discern clear patterns of the role of change agents in the diffusion of IT innovation across industries. It will also reveal any resistance of firms within the particular industry resulting from the effects of the recent Asian economic and financial crises. $^{2}$

\section{Description of Cases}

A total of 60 firms responded to my enquiries and agreed to participate in this study. Sample firms were drawn from the two major provinces (Central and East Java) using purposive sampling method for practical considerations. Moreover, this

${ }^{2}$ Indonesia has severely suffered from the unprecedented event of the economic and financial crises in 1997 98. More details about the crises see for example Arndt and Hill (1999) and Krugman (1998a, 1998b). 
GadjahMacaIntemational JamalofBusiness, January2002, Vol. 4, 16.1

non-probability sampling often gives acceptable results especially if it is conducted within a carefully controlled exploratory research (see Cooper and Schindler 2001). To reduce the possibility of narrowing the scope as a consequence of location bias, sample firms were carefully chosen on the basis of predetermined selection criteria: the size of the firm, the activities of the business, and the level of IT usage (described in Table 1).
Of the 60 firms included in the study, 58 firms are manufacturers of industrial products and 2 firms operate mainly in the service sector. The business activities of the sample firms varied, and included food processing, manufacture of wood products, machinery and metal works. Table 1 shows 29 firms operate within the 'hightech' industries (chemicals, metal works and machinery); 27 firms operate within 'low-tech' industries (food processing and

Table 1. Profile of the Sample

\begin{tabular}{|c|c|c|c|c|c|}
\hline \multirow[b]{3}{*}{ Business Activities } & \multicolumn{5}{|c|}{ Business Type } \\
\hline & $\begin{array}{c}\text { Private } \\
\text { Independent }\end{array}$ & $\begin{array}{l}\text { Agency or } \\
\text { Dealership }\end{array}$ & $\begin{array}{c}\text { Wholly-owned } \\
\text { Subsidiary }\end{array}$ & $\begin{array}{c}\text { State-owned } \\
\text { Company }\end{array}$ & \multirow[t]{2}{*}{ Total } \\
\hline & & & & & \\
\hline Food Processing & 7 & 1 & 2 & 1 & 11 \\
\hline Wood Products & 15 & & 3 & & 18 \\
\hline Chemicals & 2 & & 1 & & 3 \\
\hline Metal Works & 11 & & 2 & & 13 \\
\hline Machinery & 6 & & 5 & & 11 \\
\hline Miscellaneous & 2 & 1 & 1 & & 4 \\
\hline Total & 43 & 2 & 14 & 1 & 60 \\
\hline \multicolumn{6}{|l|}{ Size of firms } \\
\hline 1 - 20 employees & 7 & & & & 7 \\
\hline $21-100$ employees & 22 & 2 & 4 & 1 & 29 \\
\hline 101 - 150 employees & 7 & & 2 & & 9 \\
\hline 151 - 250 employees & 7 & & 8 & & 15 \\
\hline Total & 43 & 2 & 14 & 1 & 60 \\
\hline \multicolumn{6}{|l|}{ IT Usage } \\
\hline Mainly phone and fax & 8 & & & & 8 \\
\hline Stand Alone PCs & 14 & 1 & 1 & 1 & 17 \\
\hline PC Networks & 21 & 1 & 13 & & 35 \\
\hline Total & 43 & 2 & 14 & 1 & 60 \\
\hline
\end{tabular}


wood products); and another 4 firms mainly operate within miscellaneous industry, such as technical workshops, construction and engineering services.

Although the number of sample firms taken was quite small compared to the whole business population, their business type as an independent firm was closely matched to the general profile of small and medium-sized firms in Indonesia. According to Indonesia's Central Bureau of Statistics, there are about 34.2 million small and medium-sized firms; around 80 percent of these were private-independent firms.

With regard to the level of IT usage, the majority of the sample firms had installed and used personal computers in the businesses, either as stand-alone or attached to networks. Some firms relied mostly on the use of telephone and facsimile rather than on computers to manage their business activities. These firms did not suggest any specific future date for installing and using computers in their businesses.

\section{Research Findings}

Perceptual influence of the major change agents: business associates/friends, customers, academics, business consult- ants, local government authority, and people at the Ministry of Industry and Trade on IT diffusion in firms was sought by interviewing owner-managers of the firms. These selected change agents were identified as investigative variables in the diffusion of IT-based innovations (see Utomo 2001). Codified responses from the sample were then used by the researcher to identify the significant influence of these selected change agents on the diffusion of IT in firms. Table 2 shows the correlation matrix for each change agents as investigative variables and the level of its significance.

The Pearson correlation matrix for these variables is used to identify whether or not multicollinearity problems exist. The highest squared correlation amongst the independent variable was 0.30 , which existed between local government authority and linkages with academics. None of the squared correlation is close to 0.8 , suggesting that there is no evidence of multicollinearity amongst the research variables (Hair et al. 1995).

Multiple regression analysis then is used to explain the influence of change agents on IT diffusion. The dependent variable of the study refers to the extent of IT diffusion within the level of the firm, whilst the independent variables include

Table 2. Correlation Matrix for Major Change Agents

\begin{tabular}{|c|c|c|c|c|c|}
\hline Variables & (1) & (2) & (3) & (4) & (5) \\
\hline \multicolumn{6}{|l|}{ (1) Business Associates/Friends } \\
\hline (2) Customers & 0.189 & & & & \\
\hline (3) Academics & -0.147 & $0.272 *$ & & & \\
\hline (4) Local Government authority & -0.051 & 0.103 & $0.549 * *$ & & \\
\hline (5) Ministry Industry and Trade & -0.110 & $0.258 *$ & $0.465 * *$ & $0.551 * *$ & \\
\hline (6) Business Consultants & -0.144 & 0.024 & $0.309 *$ & 0.227 & 0.079 \\
\hline
\end{tabular}

* Correlation is significant at the 0.05 level (2-tailed)

** Correlation is significant at the 0.01 level (2-tailed) 
GadjahMecaIntemational JamalofBusiness, January2002, Vol. 4, Nb. 1

activities involving business associates, customers, academics, business consultants, local government authority and people at the Ministry of Industry and Trade.

Table 3 shows the result of this multiple regression. All of the research variables, except business associates/friends, are significantly related to the extent of IT diffusion within the level of the firm. The most significant variable that determines the extent of IT diffusion is business con- sultants. This suggests that the involvement of technical experts is important especially during the implementation stage of IT innovation, although the interactions of key people in firms with business consultants can be developed through informal and personal networks.

The role business consultant play in the diffusion of technological innovation within SMFs in Indonesia varies; it ranges from information facilitation to project

Table 3. Multiple Regression for Change Agents

\begin{tabular}{|c|c|c|c|c|}
\hline Dependent & Independent & Beta & $\mathbf{T}$ & p-value \\
\hline \multirow[t]{6}{*}{ Extent of IT diffusion } & Business Associates/Friends & -0.104 & -0.891 & 0.377 \\
\hline & Customers & 0.310 & 2.555 & $0.014 *$ \\
\hline & Academics & -0.329 & -2.244 & $0.029 *$ \\
\hline & Local Government Authority & -0.365 & -2.483 & $0.016 *$ \\
\hline & Ministry of Industry and Trade & 0.344 & 2.459 & $0.017 *$ \\
\hline & Business Consultants & 0.378 & 3.197 & $0.002 * *$ \\
\hline
\end{tabular}

R-squared $=0.347 ; \mathrm{F}=4.704 ; \mathrm{p}$-value $=0.001$

$* * \mathrm{p}<0.001 ; * \mathrm{p}<0.05$

Table 4. What Small Firms Expect from their Consultants?

\begin{tabular}{|c|c|c|}
\hline Firm & Area of Business & Comments \\
\hline Firm A & Metal work and foundry & $\begin{array}{l}\text { Iinvite a private business consultant come to } \\
\text { the firm on a regular basis to discuss various } \\
\text { issues related to administrative processes, } \\
\text { business strategies, and the use of new tech- } \\
\text { nologies in the firm. }\end{array}$ \\
\hline Firm B & Metal work (galvanized steel) & $\begin{array}{l}\text { This firm has benefited from the involve- } \\
\text { ment of a private consultant in developing } \\
\text { computer software applications. }\end{array}$ \\
\hline Firm C & Furniture & $\begin{array}{l}\text { I believe that the firm has gained advantage } \\
\text { from using technical expertise and experi- } \\
\text { ence offered by business consultant in mar- } \\
\text { keting products through the Internet. }\end{array}$ \\
\hline
\end{tabular}

Source: Field Interviews 
team leadership depending on the need of clients or adopters. Comments from ownermanagers of firms indicate that business consultants are facing new challenges, not only in dealing with technical matters, but also in orchestrating extensive resources (entrepreneurial skills and capital) to reach optimum benefits arising from the adoption of IT as summarized in Table 4. Ownermanagers of firms expect consultants to play an active role in facilitating the learning process to improve small business capabilities to adopt and use IT-based innovations in broad areas of firms' activities.

The statistical result as well as the comments above are consistent with the finding of Thong et al. (1996), which describe how top management supports and firms' engagement with external experts influence the extent of IT adoption within small businesses. As most small and medium-sized firms do not have a formal, internal IT department, the owners or managers usually rely on the external IT experts, such as computer vendors and business consultants to provide technical assistance until the small businesses are confident of working with IT. On number of occasions, the study found that the relationship between IT vendors and small businesses goes beyond selling the products or services, and often become part of the firm's personal network.

The MIT, with its special programs, also a variable in this study, which was found to be significant. This result suggests that the selected government policies that are designed to facilitate industry development and linkages will strongly influence the diffusion of IT amongst firms.
The selected government program, such as the national program of information kiosks for small businesses ${ }^{3}$ can be considered as positive points for the government. This program is a current joint initiative between the directorate general of trade and small-scale industry and PT. Pos Indonesia (a state owned company in the postal service) to help small businesses secure an access to computer and communication technology applications using the Indonesian postal service networks. Although information kiosks program sees an ideal way of reducing the technological gap in small businesses, the program focuses merely on preserving marketing push and pays less attention to improving other functional businesses, such as quality assurance, cost control and delivery time.

Similar to the information kiosks campaign, the MIT through the National Agency for Export Development $(\mathrm{NAFED})^{4}$ has developed on-line services to assist export-oriented businesses to obtain market information as well as overseas business partners. The agency conducts seminars, workshops, and professional training for potential exporters although the participation rate of small and medium-sized firms in this program was not disclosed.

Another potential source of influence comes from small business interactions with customers. Respondents of the study claim that their customers, mostly other private firms, become an important source of influence on decisions to adopt IT, although the level of such influence varies amongst firms or industry categories. For example, more small and medium-sized firms that sell their products to

\footnotetext{
${ }^{3}$ Further description of the objectives of information kiosks program can be found on http:// warsi.wasantara.net.id (Accessed October 2000).

${ }^{4}$ Further details about to NAFED can be found at http://www.nafed.go.id/ (Accessed October 2000).
} 
export markets tend to have Internet technology installed, compared to companies that sell most of their products on the domestic market. ${ }^{5}$ In-depth interviews with business owners or managers also revealed that the export-oriented firms have a stronger temptation to build technological image than domestic-oriented firms. Therefore, many firms are designing joint web sites on the Internet; these are commonly organized by Internet Service Providers. This assistance is needed in order to resolve telecommunication problems in Indonesia and to overcome local bandwidth constraints. This invites speculation concerning the existence of pressures from overseas trading partners in relation to the adoption and use of IT for the business.

However, this result contradicts the result of the analysis of the role of local government authority, which shows a negative direction. The absence of local government involvement in the process of IT diffusion might effect on the owners or managers' perception toward the authority. The study also finds that the linkages between small business communities and higher education or research institutions move to a negative direction toward the extent of IT diffusion. The negative directions of the two variables indicate the absence of local government and higher education institutions' involvement in IT diffusion in firms. In-depth interviews revealed that owner-managers of the firms relied on potential sources of influence other than local government and higher education institutions to acquire benefits of the technological innovation.

The result suggests that a "link and match" scheme, launched by the Ministry of National Education, do not receive sub- stantial support from the industry. This indicates that the universities or research institutions are concerned with developing IT awareness than in providing 'handson' experience in IT diffusion, despite the fact that some respondents of this study have benefited from their linkages with the manufacturing polytechnic in Bandung, West Java. This invites new challenges for the current educational system in Indonesia particularly in aligning the educational curriculum with business needs. For example, one of the respondents in the furniture industry explained that his continuous connections with academics improved his theoretical basis for managing the business. His computer skills and literacy, developed during his study in the business school, have helped him in managing the business as well.

In summary, this study has found that the influence of change agents in the diffusion of IT within small and medium-sized firms in Indonesia flows through informal institutional networks at the first stage and goes into more in-depth interactions with formal institutions. However, the results should be interpreted with caution as the data gathered may incur the possibility of having industry and situational effects. Respondents to the study came from five different industries and the interviews were conducted in various situational settings, such the timing of interviews and the social and political distress following the crises as noted earlier. These unprecedented events may have impacted on the perception of the owner-managers especially towards trustworthiness of the local government or other government supported institutions. Despite limitations of the study in relation to sampling and the 'timing' by

\footnotetext{
${ }^{5}$ Correlation between the export market orientation and the use of Internet in business is positive and significant $(r=0.356, p<0.005)$.
} 
which the study is conducted, there are some important lessons that will describe in the conclusions and implications.

\section{Conclusions and Implications}

The diffusion and adoption of IT by SMFs in Indonesia expose mixed institutional influences as identified in this study. The mechanisms by which change agents are involved in IT diffusion in the country are also unique and is claimed to be different from that is generally found in developed countries. The involvement of change agents in the diffusion of IT starts form informal situations before they can get involved in more depth and extensive interactions with owner-managers of firms. The role of change agents therefore must be considered as a necessary but not sufficient condition in the diffusion of IT within SMFs in general.

Moreover, the institutional factors can be used either as the major source of IT knowledge or the facilitator for IT diffusion although there is evidence to support the critical role played by these factors in both private and public institutions. The study concludes with observations and conjectural evidence regarding the crucial role played by both consultants and the government at the ministry level as the paradigmatic institutions, from which SMFs could learn, in terms of their power, expertise and experience in relation to the adoption of IT-based innovations.

Two major policy implications can be derived from this study. First, there is little doubt that owner-managers will oppose potential benefits of IT diffusion in firms. Improved IT knowledge amongst owner-managers of the firms, as identified in the previous studies, might be important in accelerating the diffusion of technological innovations. The creation of 'triple helix' through building collaborative efforts of government authorities, industry groups and perhaps higher education institutions becomes another necessary condition to accelerate the adoption and use of IT-based innovations within small and medium-sized firms in Indonesia.

Second, some firms are already obtaining useful technical assistance from private consultants, especially during the initial stage of IT implementation. While large firms may commonly make extensive use of the services provided by consultants and have learned how to manage the relationship involved, SMFs may not follow the same direction. If technical consultants are needed to help small firms to adopt IT, then attention needs to be paid to how these change agents may deliver their services to SMFs at subsidized rates and how their activities may be controlled and monitored.

\section{References}

Arndt, H.W., and H. Hill. 1999. Southeast Asia's Economic Crisis: Origins, Lessons, and the Way Forward. St. New York: Martin's Press, and Singapore: Institute of Southeast Asian Studies.

Bode, S., and J. Burn. 2000. SMEs and the role of consultants in establishing e-business: A case analysis. Proceeding of the Third CollECTer Conference on Electronic Commerce. NZ: Wellington. 
GadjahMedaIntemational JamalofBusiness, January2002, Vol. 4, Nb. 1

Chan, C., and P.M.C. Swatman. 1999. E-Commerce implementation in Australia; A case study approach. Proceeding of the Third CollECTer Conference on Electronic Commerce. Wellington, NZ.

Cooper, R.D., and S.P. Schindler. 2001. Business Research Methods. $7^{\text {th }}$ Ed. Boston: McGraw-Hill-Irwin.

Dodgson, M., and J. Bessant. 1996. Effective Innovation Policy: A New Approach. Routledge, New York.

Etzkowitz, H., A. Webster, C. Gebhardt, and B.R.C. Terra. 2000. The future of the university and the university of the future: Evolution of ivory tower to entrepreneurial paradigm. Research Policy 29 (2) (February).

Etzkowitz, H., and L. Leydesdorff. 2000. The dynamics of innovation: from National systems and 'mode 2' to a triple helix of university-industry-government relations. Research Policy 29 (2) (February).

Gregor, S., and K. Jones. 1997. Enabling electronic commerce in agribusiness: The initial stage of a diffusion process. In Proceedings of the first Annual CollECTer Workshop on Electronic Commerce (October). Adelaide.

Hair Jr, J.F., R.E. Anderson, R.L. Tatham, and W.C. Black. 1995. Multivariate Data Analysis. $4^{\text {th }}$ Ed. Englewood Cliffs, New Jersey: Prentice-Hall.

Hanna, N., K. Guy, and E. Arnold. 1995. The Diffusion of Information Technology: Experience of Industrial Countries and Lessons for Developing Countries. Washington, D.C.: The World Bank.

Hanna, N., S. Boyson, and S. Gunaratne. 1996. The East Asian Miracle and Information Technology: Strategic Management of Technological Learning. Washington, D.C.: The World Bank.

Harrison, D.A., P.P. Mykytyn, and C.K. Riemenschneider. 1997. Executive decision about adoption of information technology in small business: Theory and empirical tests. Information Systems Research 8 (2) (June).

Holman, P., and T. Devane (Eds.) 1999. The Change Handbook: Group Method for Shaping the Future. San Francisco: Berrertt-Koehler Publishers, Inc.

Hughes, J., S. Kristoffersen, J. O'Brien, and M. Rouncefield. 1996. The organisational politics of meeting and their technology: Two case studies of video supported communication. In Kautz and Pries-Heje: Diffusion and Adoption of Information Technology. Melbourne: Chapman \& Hall.

Indonesian Central Bureau of Statistics (BPS). 1997. Industry survey 1985-1997. Unpublished Data.

Jandos, J., and K. Uhlir. 2000. EDI/electronic commerce applications of customer-toadministration type: Czech customs case. Proceeding of the First Annual Global Information Technology World Conference (11-13 June). Memphis, TN. 
Utomo-The Influence of ChangeAgents on IIDiffusion inFims

Kangas, K. 2000. Perception of IT and management infrastructure in multinationals operating in Russia. Proceeding of the First Annual Global Information Technology World Conference (11-13 June). Memphis, TN.

King, J.L., V. Gurbaxani, L.K. Kraemer, W.F. McFarlan, S.K. Raman, and S.C. Yap. 1994. Institutional factors in information technology innovation. Information Systems Research 5 (2) June.

Krugman, P. 1998. What happened with Asia. http://web.mit.edu/krugman/www/ DISINTER.html (accessed on 28 September 2000).

.1998. Will Asia bounce back? http://web.mit.edu/krugman/www/suisse.html (accessed on 30 October 2000).

Lai-Yee, T., and S. Pendse, S. 1997. An empirical evaluation of web page design and consumer behavior. Proceeding of the First CollECTer Conference on Electronic Commerce (October 3). Adelaide.

Montealegre, R. 1999. A temporal model of institutional interventions for information technology adoption in less-developed countries. Journal of Management Information Systems 16 (1) (Summer).

O'Callaghan, R. 1998. Technology diffusion and organizational transformation. In Larsen, T.J. and McGuire, E.: Information Systems Innovation and Diffusion: Issues and Directions. Hershey, PA: Idea Group Publishing.

Parker, C., and P.M.C. Swatman. 1997. The importance of EDI education: A survey of Australian SMFs. Proceeding of the First CollECTer Conference on Electronic Commerce (October 3) Adelaide.

Peter, D.R. 1999. Empowering teacher trainees to communicate ideas using IT. Proceeding of the Conference on Information Technology in Asia (September). Kuching (Sarawak), Malaysia.

Rogers, E.M. 1995. Diffusion of Innovations. $4^{\text {th }}$. Ed. Sydney: The Free Press.

Ridzuan, A., and N.H. Alias. 1999. Attitudes, beliefs and behavior of computer-users among lecturer in teachers' training college in Sabah. Proceeding of the Conference on Information Technology in Asia (September). Kuching (Sarawak), Malaysia.

Sam, H.K., A.A. Ridzuan, A. Awit, and MH.A. Rahman. 1999. Computers in school administration: A study amongst secondary school administrators in Rompin District, Pahang. Proceeding of the Conference on Information Technology in Asia (September). Kuching (Sarawak), Malaysia.

Swan, J., S. Newell, and M. Robertson. 1999. Central agencies in the diffusion and design of technology: A comparison of the UK and Sweden. Organization Studies 2 (6).

The World Bank. 2000. World Development Report 2000-01: Attacking Poverty. Washington D.C.: Oxford University Press and The World Bank. (http:// www.worldbank.org/poverty/wdrpoverty/ Accessed on 7 September 2000). 
GadjahMacaIntemational JoumalofBusiness, January2002, Vol. 4, Nb. 1

Thong, J.Y.L., and C.S. Yap. 1996. Information technology adoption by small business: An empirical study. In Kaultz, K., and J. Pries-Meje: Diffusion and Adoption of Information Technology. London: Chapman \& Hall.

Thong, J.Y.L., C.S. Yap, and K.S. Raman. 1996. Top management support, external expertise and information systems implementation in small businesses. Information Systems Research 7 (2).

Utomo, H. 2001. The diffusion of information technology innovations within small and medium-sized firms in Indonesia. Doctoral Dissertation.

Utomo, H., and M. Dodgson. 2000. The impact of IT diffusion within small firms. Gadjah Mada International Journal of Business 2 (1) (January).

Utomo, H. 2000. Some preliminary findings on the diffusion of information technology within small and medium-sized firms in Indonesia. Proceeding of the First Annual Global Information Technology World Conference (11-13 June). Memphis, TN.

Yin, R.K. 1993. Applications of Case Study Research. Newbury Park, C.A.: Sage Publications.

Yin, R.K. 1994. Case Studies Research: Design and Methods. Berely Hils, C.A.: Sage Publications.

Yap, C.S., J.Y.L. Thong, and K.S. Raman. 1994. Effect of government incentives on computerization in small business. European Journal of Information Systems 3 (3).

Yap, C.S., and J.Y.L. Thong. 1997. Programme evaluation of a government information technology programme for small businesses. Journal of Information Technology 12 (2). 